\title{
A Rare Case of Tracheobronchomegaly: The Mounier - Kuhn Syndrome
} Kilaru $D^{*}$, Stadler C and Alaverdian A

Nassau University Medical Center, East Meadow, New York, USA

*Corresponding author: Kilaru D, Internal Medicine Resident, Nassau University Medical Center, East Meadow, New York, USA, Tel: +5165726501; E-mail: dkilaru@numc.edu

Received date: June 27, 2016; Accepted date: July 06, 2016; Published date: July 11, 2016

Copyright: (c) 2016 Kilaru D, et al. This is an open-access article distributed under the terms of the Creative Commons Attribution License, which permits unrestricted use, distribution, and reproduction in any medium, provided the original author and source are credited.

Keywords: Pneumonia; Recurrent respiratory tract infections; Cough; Bronchiectasis

\section{Introduction}

Mounier-Kuhn syndrome is a chronic airway disease characterized by dilatation of the trachea and bronchi, recurrent respiratory tract infections and bronchiectasis [1]. It was first described by MounierKuhn is 1932 with fewer than 100 cases reported in the medical literature [2]. Here we present one such case of Mounier-Kuhn syndrome.

\section{Case Presentation}

A 36-year-old Caucasian male presented to the emergency department with shortness of breath, fevers, pleuritic chest pain and productive cough for 10 days. He was treated for pneumonia with four days of azithromycin prior to admission. Patient had a 30-pack-year smoking history and worked in construction. Vitals were BP 121/86, $\mathrm{HR} 88, \mathrm{RR} 18, \mathrm{SpO}_{2} 86 \%$ on room air with diffuse bilateral wheezing and rhonchi. The laboratory findings included a WBC count of 16.32 $\mathrm{K} / \mathrm{mm}^{3}$ with neutrophilic predominance and a bicarbonate of 36 $\mathrm{mmol} / \mathrm{L}$. HIV, alpha-1-anti-trypsin, Cystic fibrosis screening mutations, and aspergillus antibody testing were all negative. Chest $\mathrm{x}$ ray revealed persistent basilar predominant thickened and prominent interstitial pulmonary markings, suggestive of chronic lung disease. More patchy/nodular opacities at both lung bases, especially on the left, may represent developing lower lobe pneumonia (Figure 1).

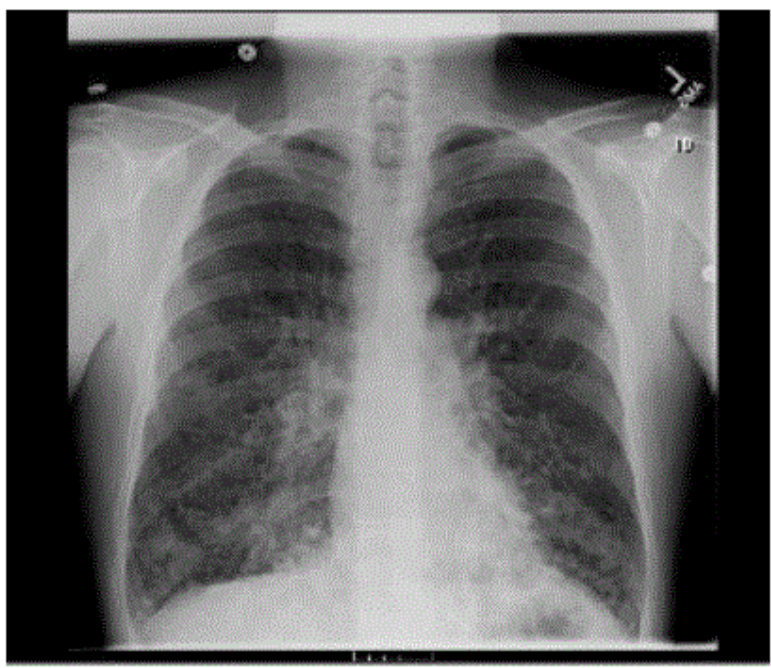

Figure 1: Chest x-ray of developing lower lobe pneumonia.

Patient's prior pulmonary function tests were consistent with obstructive ventilatory impairment (Table 1 and Figure 2).

\begin{tabular}{|l|l|l|l|l|l|l|l|}
\hline \multirow{2}{*}{ Lung Mechanics } & \multicolumn{4}{l}{ Pre-Bronch } & \multicolumn{3}{l|}{ Post-Bronch } \\
\cline { 2 - 8 } & Units & Actual & Pred & \%Pred & Actual & \%Pred & \%Change \\
\hline FVC & L,bpts & 3.56 & 5.46 & 65 & - & - & - \\
\hline FEV1 & L,bpts & 1.6 & 4.2 & 38 & - & - & - \\
\hline FEV1/FVC & $\%$ & 44.92 & 76.98 & 58 & - & - & - \\
\hline FEF25\% & L/s & 1.41 & 8.48 & 17 & - & - & - \\
\hline FEF50\% & L/s & 0.83 & 6.02 & 14 & - & - & - \\
\hline FEF75\% & L/s & 0.35 & 3.13 & 11 & - & - & - \\
\hline FEF MAX & L/s & 4.92 & 9.67 & 51 & - & - & - \\
\hline FEF25\%-75\% & L/s & 0.67 & 4.33 & 15 & - & - & - \\
\hline FIVC & L,bpts & 3.34 & - & - & - & - & - \\
\hline FIF50\% & L/s & 3.36 & - & - & - & - \\
\hline
\end{tabular}


Citation: Kilaru D, Stadler C, Alaverdian A (2016) A Rare Case of Tracheobronchomegaly: The Mounier-Kuhn Syndrome. Lung Dis Treat 2: 111. doi:10.4172/2472-1018.1000111

Page 2 of 3

\begin{tabular}{|c|c|c|c|c|c|c|c|}
\hline FEF50/FIF50 & $\%$ & 24.61 & - & - & - & - & - \\
\hline MVV & $\mathrm{L} / \mathrm{min}, \mathrm{bpts}$ & 61.71 & 150.16 & 41 & - & - & - \\
\hline PImax/MIP & $\mathrm{cmH}_{2} \mathrm{O}$ & - & -124.3 & - & - & - & - \\
\hline PEMAX/MEP & $\mathrm{cmH}_{2} \mathrm{O}$ & - & 232.98 & - & - & - & - \\
\hline Lung volumes & Units & Actual & Pred & $\%$ Pred & - & - & - \\
\hline vc & L,bpts & 3.62 & 5.46 & 66 & - & - & - \\
\hline IC & L,bpts & 3.17 & 3.37 & 94 & - & - & - \\
\hline ERV & L,bpts & 0.45 & 2.09 & 22 & - & - & - \\
\hline TV & L,bpts & 1.47 & - & - & - & - & - \\
\hline FRC & L,bpts & 6.06 & 4.11 & 146 & - & - & - \\
\hline $\mathbf{R V}$ & L,bpts & 5.61 & 2.02 & 278 & - & - & - \\
\hline TLC & L,bpts & 9.23 & 7.48 & 123 & - & - & - \\
\hline RV/TLC & $\%$ & 60.75 & 26.98 & 225 & - & - & - \\
\hline RAW & $\mathrm{cmH}_{2} \mathrm{O} / \mathrm{L} / \mathrm{s}$ & - & $0.20-2.50$ & - & - & - & - \\
\hline Sgaw & $\mathrm{L} / \mathrm{s} / \mathrm{cmH}_{2} \mathrm{O}$ & - & $0.11-0.40$ & - & - & - & - \\
\hline Diffusion Capacity & Units & Actual & Pred & $\%$ Pred & - & - & - \\
\hline Dsb & $\mathrm{ml} / \mathrm{min} / \mathrm{mmHg}$ & 27.63 & 31.72 & 87 & - & - & - \\
\hline Vasb & L,bpts & 6.74 & 7.48 & 90 & - & - & - \\
\hline D/Vasb & $\mathrm{ml} / \mathrm{min} / \mathrm{mmHg} / \mathrm{L}, \mathrm{bpts}$ & 4.1 & 4.24 & 97 & - & - & - \\
\hline
\end{tabular}

Table 1: Pre-bronch and post-bronch values.

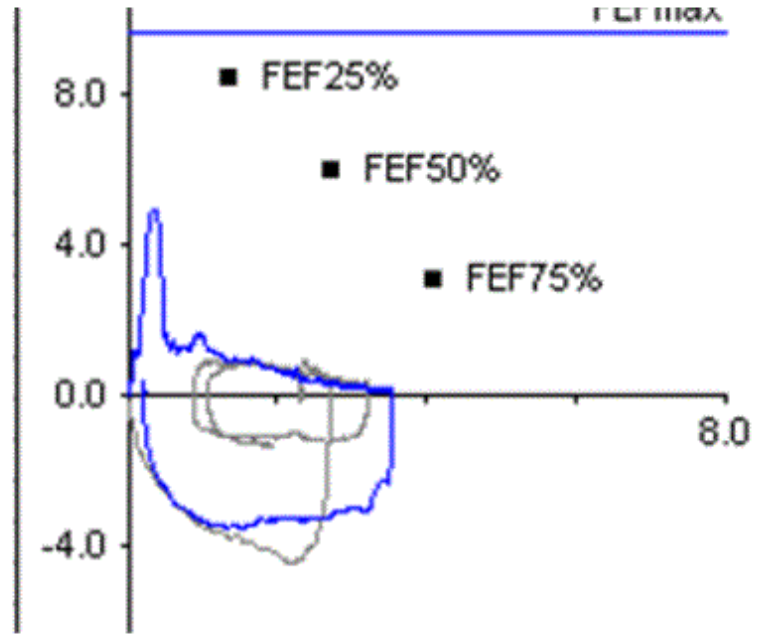

Figure 2: Pulmonary function tests consistent with obstructive ventilatory impairment.
CT thorax showed diffuse hypertrophy of the tracheobronchial cartilaginous rings with tracheobronchial diverticulosis and extensive bilateral bronchiectasis (Figure 3).

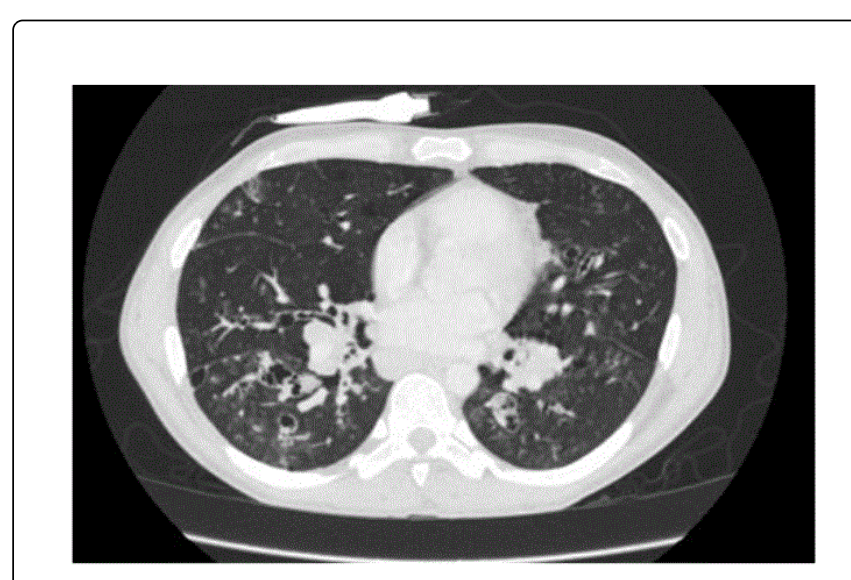

Figure 3: CT thorax showed diffuse hypertrophy of the tracheobronchial cartilaginous rings.

Tracheal diameter was measured to be $33.6 \mathrm{~mm}$ (Figure 4), the right and left mainstem bronchi were $32.1 \mathrm{~mm}$ and $30.6 \mathrm{~mm}$, respectively. This confirmed the diagnosis of Mounier-Kuhn syndrome. The patient 
Citation: Kilaru D, Stadler C, Alaverdian A (2016) A Rare Case of Tracheobronchomegaly: The Mounier-Kuhn Syndrome. Lung Dis Treat 2: 111.

Page 3 of 3

underwent bronchoscopy that showed an enlarged trachea and mainstem bronchi, with prominent cartilaginous rings (Figure 5).

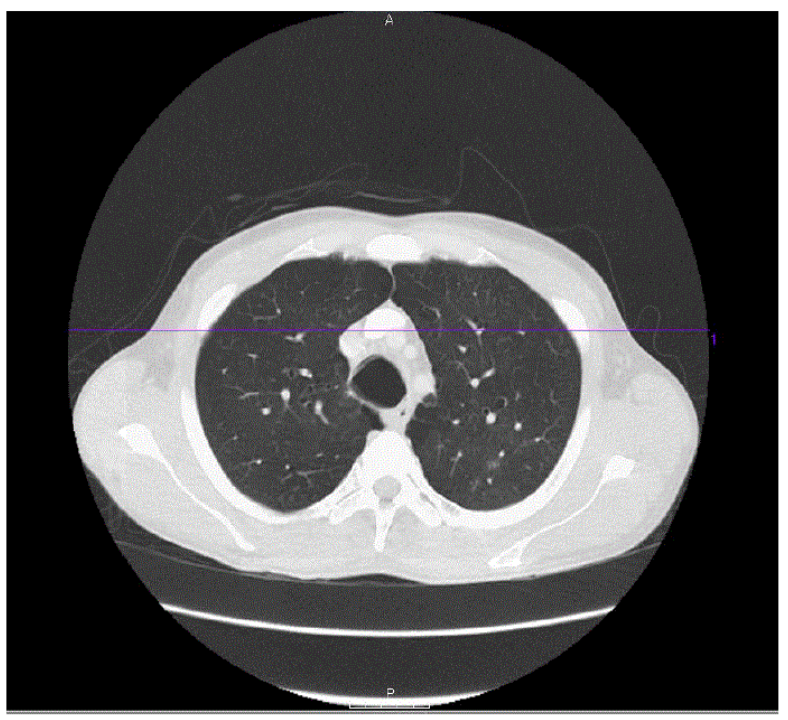

Figure 4: Tracheal diameter of the right and left mainstem bronchi.

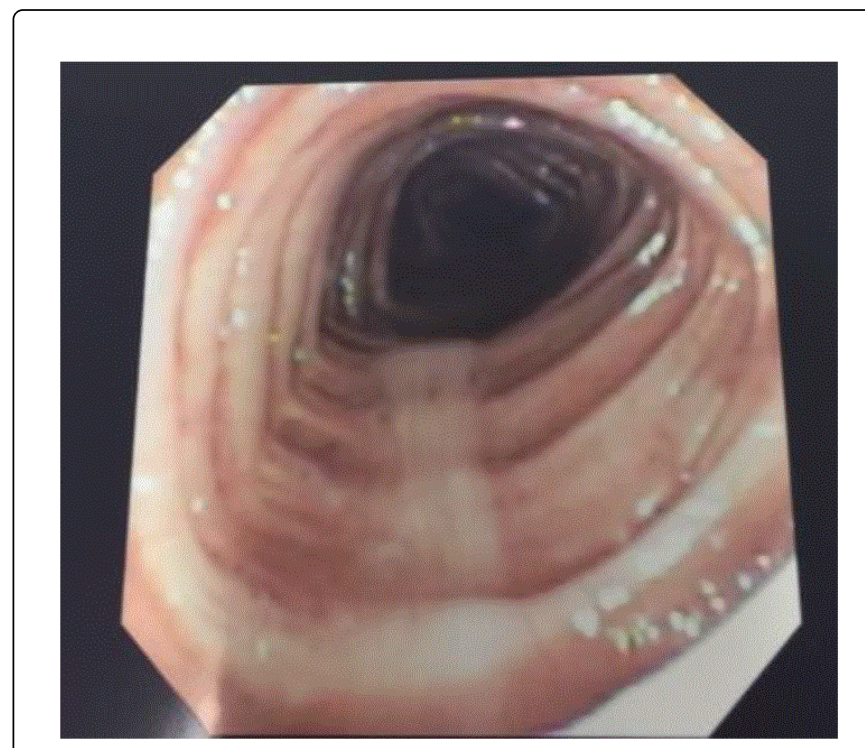

Figure 5: Bronchoscopy of an enlarged trachea and mainstem bronchi, with prominent cartilaginous rings.
Respiratory culture grew alpha haemolytic streptococcus. The patient was treated for community acquired pneumonia and COPD exacerbation and was discharged home.

\section{Discussion}

Mounier-Kuhn syndrome is characterized by atrophy of longitudinal elastic fibers with thinning of the muscularis mucosa that results in dilation of the membranous and cartilaginous portions of the trachea and main bronchi [1]. Three subtypes exist. In Type 1, there is slight symmetric dilation in the trachea and main bronchi. In Type 2, the dilatation and diverticula are more distinct; and in Type 3 the diverticula extend to the more distal bronchi [2]. Due to this dilatation, patients have an ineffective cough and impaired mucociliary clearance leading to recurrent infections. In adults the diagnosis is made on CT scan if the trachea is $>30 \mathrm{~mm}$, the right main bronchus is $>20 \mathrm{~mm}$, and the left main bronchus is $>18 \mathrm{~mm}$ [2]. Treatment is supportive and includes mucolytic treatment and postural drainage to counteract the impaired mucociliary clearance [1]. Patients should receive pneumococcal and yearly influenza vaccines regardless of age and be counseled in smoking cessation [1,3]. Because of easily collapsible airways, tracheobronchoplasty and airway stenting have been performed. Lung transplant has also been reported twice in patients with Mounier Kuhn syndrome [1].

\section{Conclusion}

This case presentation is an example of a patient that was misdiagnosed as a case of COPD rather than Mounier-Kuhn syndrome. This was due to a confounding variable of smoking, however, the patient's young age and enlarged airways on CT thorax revealed his diagnosis of Mounier-Kuhn syndrome which also explained his recurrent pneumonias.

\section{References}

1. Krustins E, Kravale Z, Buls A (2013) Mounier-Kuhn syndrome or congenital tracheobronchomegaly: a literature review. Respiratory Medicine 107: 1822-1828.

2. Celik B, Bilgin S, Yuksel C (2011) Mounier-Kuhn syndrome: a rare cause of bronchial dilation. Tex Heart Inst J 38: 194-196.

3. Lerner C, Patel R, Julka K (2014) The man with the Large Trachea: Mounier-Kuhn Syndrome. The American Journal of Medicine 127: 1072-1074. 